\title{
Publisher Correction to: Teachers as redesigners of curriculum to teach mathematics through problem posing: conceptualization and initial findings of a problem-posing project
}

\author{
Jinfa Cai ${ }^{1}$ Stephen Hwang ${ }^{1}$
}

Published online: 13 April 2021

(c) FIZ Karlsruhe 2021

Correction to: ZDM - Mathematics Education

https://doi.org/10.1007/s11858-021-01252-3

The publication of this article unfortunately contained a mistake. The last word was missing in the article title. Please see the correct article title above.

The original article has been corrected.

Publisher's Note Springer Nature remains neutral with regard to jurisdictional claims in published maps and institutional affiliations.

The original article can be found online at https://doi.org/10.1007/ s11858-021-01252-3.

$\triangle$ Jinfa Cai

jcai@udel.edu

1 University of Delaware, 437 Ewing Hall, Newark, DE 19716, USA 